\title{
DSP Implementation of the Multiple Reference Frames Theory for the Diagnosis of Stator Faults in a DTC Induction Motor Drive
}

\author{
Sérgio M. A. Cruz, Member, IEEE, Hamid A. Toliyat, Senior Member, IEEE, and \\ A. J. Marques Cardoso, Senior Member, IEEE
}

\begin{abstract}
This paper deals with the use of a new diagnostic technique based on the multiple reference frames theory for the diagnosis of stator winding faults in a direct-torque-controlled (DTC) induction motor drive. The theoretical aspects underlying the use of this diagnostic technique are presented but a major emphasis is given to the integration of the diagnostic system into the digital-signal-processor (DSP) board containing the control algorithm. Taking advantage of the sensors already built in the drive for control purposes, it is possible to implement this diagnostic system at no additional cost, thus giving a surplus value to the drive itself. Experimental results show the effectiveness of the proposed technique to diagnose stator faults and demonstrate the possibility of its integration in the DSP board.
\end{abstract}

Index Terms-Digital signal processors (DSPs), fault diagnosis, induction motor drives.

\section{INTRODUCTION}

$\mathbf{F}$ AULTS in the stator windings of three-phase induction machines represent a significant part of the failures that arise during the motor lifetime. When these motors are fed from inverters, the situation tends to become even worse due to the voltage stresses imposed by the fast switching of the power semiconductors of the inverter, which often lead to a degradation of the turns insulation and, ultimately, to winding short circuits [1]-[5]. Consequently, some research studies have been conducted in the last few years concerning the impact of closed-loop drives (vector-controlled drives) on the diagnosis of stator faults in induction motors [6]-[8].

Some of the diagnostic techniques usually used to detect stator winding faults are based on the measurement of the negative-sequence component of the supply currents. When the motor is part of a vector-controlled drive, the outputs of the controllers tend to compensate the asymmetry of the machine by shifting the unbalance of the supply currents to the supply voltages. This results in a strong attenuation of the negative-sequence component of the motor supply current, thus compromising the diagnosis process if it is based solely on the monitoring of the motor supply currents.

Manuscript received August 21, 2003. This work was supported in part by PRODEP III. Paper no. TEC-00217-2003.

S. M. A. Cruz and A. J. M. Cardoso are with the Department of Electrical and Computer Engineering, University of Coimbra, Coimbra P-3030-290, Portugal (e-mail: smacruz@ieee.org; ajmcardoso@ieee.org) and also with the Instituto de Telecomunicacões, Coimbra P-3030-290, Portugal.

H. A. Toliyat is with the Department of Electrical Engineering, Texas A\&M University, College Station, TX 77843-3128 USA (e-mail: toliyat@ee.tamu.edu).

Digital Object Identifier 10.1109/TEC.2005.845531
In [7], the use of a neural network scheme is proposed, already developed for line-fed induction motors, to detect the fault. Two line-to-line voltages and two current signals are sampled with a data acquisition (DAQ) board and the diagnosis is performed on a computer. In [8], a diagnostic technique based on the injection of a high-frequency carrier signal is proposed to detect the fault in a vector-controlled drive. The carrier signal is superimposed on the outputs of the current regulators, being the fault detection based on the measurement of the negative-sequence component of the motor supply current carrier signal.

Despite these previous studies having addressed closed-loop drives, none of them has dealt with direct-torque-controlled (DTC) induction motor drives, widely used in industry today. This is a relevant issue as the operating philosophy of a DTC drive is quite different from a vector-controlled machine. Thus, some of the techniques presented for vector-controlled machines may not work for DTC drives. As an example, it can be said that the technique presented in [8] for a vector-controlled drive is unfeasible in a DTC drive. In fact, a DTC drive contains only one two-level hysteresis controller for flux control and a three-level hysteresis controller for torque control. These controllers, in conjunction with a switching table, generate the output signals to the gates of the power switches of the inverter, thus being impossible to superimpose any signal to these outputs, at least in a straightforward manner.

This paper is intended to present the implementation of a new diagnostic technique of stator faults in a DTC three-phase induction motor drive, emphasizing the aspects related to its integration in the DSP board already used for control purposes.

\section{MultiPle REFERENCE Frames THEORY}

\section{A. Introduction}

The first public reference to the method of multiple reference frames dates back to 1968 [9]. In that work, the method is used for the analysis of steady-state modes of symmetrical induction machinery with any periodic phase voltages applied to the stator. After this initial work, this method was also used for the analysis of rectifier-inverter induction motor drives. Later on, the method was applied to the analysis of the behavior of different kinds of electrical machines and drives such as a multistack variable-reluctance stepper motor, an unsymmetrical two-phase induction machine, a single-phase induction machine with a shifted auxiliary winding, and a brushless de drive [10], [11].

Although the multiple reference frames theory has often been used as a basis for analysis, more recently, it has also 
been used as a tool to control a permanent-magnet synchronous motor (PMSM). In [12], the proposed control system contains two parts: one of them is a multiple reference-based estimator, which decomposes the measured currents to appropriate frames of reference; the other part, which consists in a multiple reference frame integral feedback controller, forces the actual current components to match their commands.

In this paper, the use of the multiple reference frames theory is extended to the diagnosis field, in particular, to the diagnosis of stator faults in a DTC induction motor drive.

\section{B. Diagnosis of Stator Faults [13]}

To use this theory for the diagnosis of stator faults, and to generalize the obtained conclusions for different motors in regards to the winding arrangement, type of connection, number of poles, rated power, etc., two simulation models were developed. The first is a detailed model, based on the use of the winding function theory, and is able to simulate the behavior of motors with any stator winding arrangement introduced by the user [14], [15]. The other developed model is a simplified one, in $d-q-0$ coordinates, used to demonstrate some mathematical relations between the different quantities used later on for the diagnosis of the fault. In this simplified model, the winding of the phase affected by the fault is split into two subwindings. After this, the flux and voltage equations for all of the stator and rotor windings are written. After some mathematical manipulations, these equations are transformed to $d-q-0$ coordinates, in an arbitrary reference frame. Although the development of this model follows closely the one presented in [16], the initial assumptions are different, namely the ones related with the distribution of the leakage inductances between the subwindings of the affected phase. In fact, several researchers have reported difficulties in finding a good agreement between the experimental value of the short-circuit current and the one obtained by simulation. Experimental results conducted at a reduced voltage in a special test machine have shown that this is due to the wrong assumption that the leakage inductances of the subwindings are directly proportional to the number of turns of these subwindings. A much better approximation of the reality is to consider a quadratic relation between these two parameters in each coil of the winding and then sum the contribution of all the coils of that phase.

Using the simplified model, (1) is obtained

$$
\begin{aligned}
{\left[u_{s}\right]_{d q 0} } & -\frac{k}{3}\left[\begin{array}{c}
\left(-2 k L_{l s}-3 L_{m s}\right) \cos \theta_{a} \\
\left(2 k L_{l s}+3 L_{m s}\right) \sin \theta_{a} \\
-k L_{l s}
\end{array}\right] \frac{d i_{f}}{d t} \\
+ & \frac{k}{3} R_{s}\left[\begin{array}{c}
2 \cos \theta_{a} \\
-2 \sin \theta_{a} \\
1
\end{array}\right] i_{f} \\
= & {\left[R_{s}\right]\left[i_{s}\right]_{d q 0}+\left[L_{s}\right] \frac{d}{d t}\left[i_{s}\right]_{d q 0}+\left[L_{s r}\right] \frac{d}{d t}\left[i_{r}\right]_{d q 0} } \\
& +\omega_{a}\left[\begin{array}{ccc}
0 & -L_{s} & 0 \\
L_{s} & 0 & 0 \\
0 & 0 & 0
\end{array}\right]\left[i_{s}\right]_{d q 0} \\
& +\omega_{a}\left[\begin{array}{ccc}
0 & -L_{m} & 0 \\
L_{m} & 0 & 0 \\
0 & 0 & 0
\end{array}\right]\left[i_{r}\right]_{d q 0}
\end{aligned}
$$

where $\left[u_{s}\right]_{d q 0},\left[i_{s}\right]_{d q 0}$, and $\left[i_{r}\right]_{d q 0}$ represent the stator voltages, the stator currents, and rotor currents referred to the stator windings, respectively; $i_{f}$ is the short-circuit current; and $k$ is the ratio of shorted turns in relation to the total number of turns in series per phase. $\theta_{a}=\omega_{a} / 2 \pi$ stands for the transformation angle and all of the other quantities have the usual meaning.

The second term of (1) is the same as the one for the case of a healthy motor. The first term can be regarded as the sum of the supply voltages of the motor plus two additional voltage components introduced by the fault. Because the short-circuit current can be given by a sinusoidal function at the fundamental supply frequency, these two additional components, in a synchronous reference frame, are equal to the sum of a constant term with a sinusoidal function at the double supply frequency. On the other hand, the motor supply currents contain a positive- and a negative-sequence component due to the presence of the stator fault. Therefore, the stator currents in $d-q$ axes are given by

$$
\left[i_{s}\right]_{d q}=\left[i_{s}\right]_{d q}^{+}+\left[i_{s}\right]_{d q}^{-}
$$

where superscripts + and - stand for the positive- and negative-sequence components, respectively. If a synchronous reference frame rotating in the clockwise direction is considered, the component $\left[i_{s}\right]_{d q}^{-}$will appear as constant and the components $\left[i_{s}\right]_{d q}^{+}$as a sinusoidal function at the double supply frequency. Conversely, in a synchronous reference frame rotating in the counterclockwise direction, $\left[i_{s}\right]_{d q}^{+}$appears as constant and $\left[i_{s}\right]_{d q}^{-}$ as a sinusoidal function at the double supply frequency. The same reasoning applies to the rotor currents referred to the stator circuits. Consequently, the fact that the current components appear as constants in a reference frame synchronized with them can be exploited to easily measure or eliminate those components.

In addition, considering the rotor speed constant, the principle of superposition can be applied. Hence, in each synchronous reference frame, (1) can be split into two equations: one resulting from the grouping of the constant terms in both members of the equation, and another one, resulting from the grouping of the sinusoidal functions at the double supply frequency. If the quantities in the equation are averaged, only the constant components will remain in the resulting equations, thus being easily measured and/or removed. If the stator currents are expressed first in a clockwise synchronous reference frame and the constant terms are removed from each one of the $d-q$ current components and subsequently transformed to a counterclockwise synchronous reference frame, the resulting $d-q$ current components can be regarded as the sum of the value they would have in the absence of faults, plus an additional component due to the presence of the stator fault

$$
\begin{aligned}
& i_{d s}^{+}=i_{d s}^{h}+i_{d s}^{f} \\
& i_{q s}^{+}=i_{q s}^{h}+i_{q s}^{f}
\end{aligned}
$$

where the superscripts $h$ and $f$ stand for the healthy condition of the motor and additional current components due to the presence of the fault, respectively.

In order to calculate the fault indicator, which is defined by the vector $\Delta \underline{i}^{f}=i_{d s}^{f}+j i_{q s}^{f}$, it is necessary to calculate $i_{d s}^{h}$ and $i_{q s}^{h}$ for the specific value of rotor speed at which the motor is running. Using the motor parameters determined by the drive 


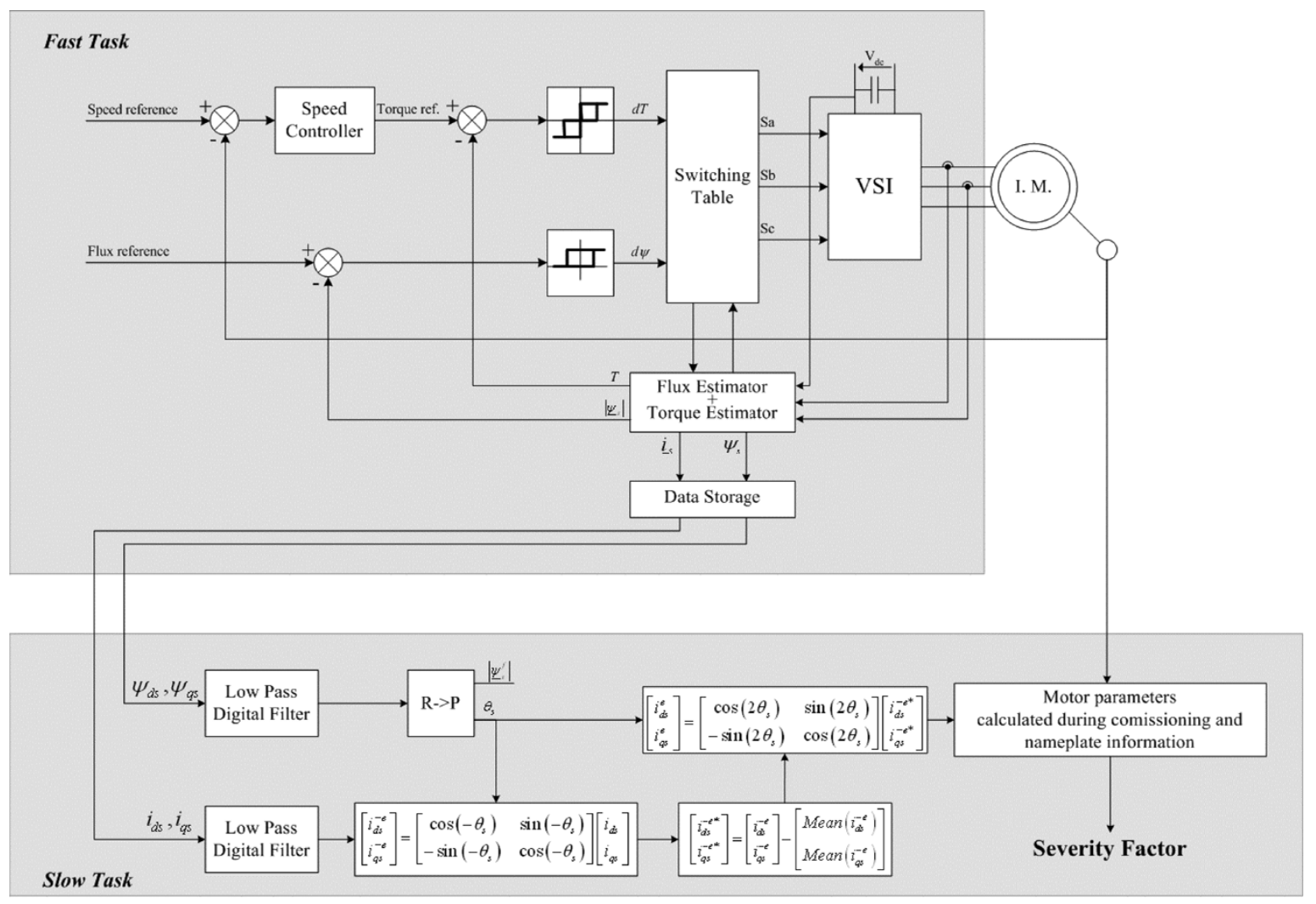

Fig. 1. Block diagram of the implemented system. A fast task is devoted to the control while a slower task is dedicated to the diagnosis of the fault.

during the commissioning phase, the calculation of these quantities is straightforward.

The final step of the diagnostic process is the definition of an adequate severity factor, which corresponds to the normalization of the modulus of the fault vector. Because analytical and simulation studies have proved that the short-circuit current is limited mainly by the resistances and leakage reactances of the windings of the motor, an appropriate normalization quantity appears to be the locked-rotor current of the motor $I_{l r c}$. The severity factor can now be defined as

$$
\text { Severity Factor }=\frac{\left|\Delta \underline{i}^{f}\right|}{I_{l r c}} \times 100 \%
$$

\section{InTEgration of The Diagnostic System}

\section{A. General Remarks}

The presence of a digital signal processor (DSP) in a drive system as well as the presence of current and voltage sensors opens the door to the integration of the diagnostic system into the hardware and software already developed for control purposes. This means that the diagnostic procedure can be incorporated into the system at no additional cost.

In a DTC induction motor drive, usually there are two current sensors to measure the motor supply currents and one voltage sensor to measure the dc-link voltage. With this information, the line-to-line voltages can easily be reconstructed by knowing the positions of the six switches of the inverter. The speed is another quantity already available/estimated due to the presence of a speed loop in the drive. Consequently, all of the information needed to implement the diagnostic technique is already present in the control system.

\section{B. Implementation of the Diagnostic Technique}

Fig. 1 shows a detailed block diagram of the implemented system.

Due to the requirement of a very short sampling period to accurately estimate the stator flux and the electromagnetic torque developed by the motor, the critical calculations involved in the estimation process were implemented in an interrupt routine. This routine also includes an additional module to store the $d-q$ components of the stator current and estimated stator flux, which will be used later on by the diagnosis module. The main program contains the remaining modules of the DTC control algorithm and a slow task where the diagnostic algorithm is implemented. To avoid degradation of the performance of the DTC drive, this slow task is subdivided into four main subtasks, each one being executed in a cycle of the main program. The subtasks can be classified in general terms as follows: i) filtering; ii) coordinate transformation to the clockwise synchronous reference frame; iii) averaging, subtraction, and coordinate transformation to the counterclockwise synchronous reference frame; and iv) calculation of the severity factor. A detailed description of each one of these subtasks is given in the following.

1) Filtering: The diagnostic technique based on the multiple reference frames theory uses the information contained in the fundamental components of the stator flux linkage and supply currents of the motor. Consequently, other spectral components 
present in these quantities are superfluous and should be eliminated to increase the accuracy of the obtained results. To perform this task, a digital filter is used to filter out all of these harmonics, thus isolating the fundamental components of those signals. Experimental tests with different types of filters showed that the fundamental component can be effectively isolated from the overall signal using a low-pass second-order Butterworth digital filter, whose transfer function is given by

$$
H(z)=\frac{Y(z)}{X(z)}=\frac{b_{0}+b_{1} z^{-1}+b_{2} z^{-2}}{a_{0}+a_{1} z^{-1}+a_{2} z^{-2}}
$$

with $b_{0}=\Omega_{c}^{2}, b_{1}=2 b_{0}, b_{2}=b_{0}, a_{0}=4 F_{s}^{2}+2 \sqrt{2} \Omega_{c} F_{s}+\Omega_{c}^{2}$, $a_{1}=-8 F_{s}^{2}+2 \Omega_{c}^{2}$, and $a_{2}=4 F_{s}^{2}-2 \sqrt{2} \Omega_{c} F_{s}+\Omega_{c}^{2}$. In these equations, $\Omega_{c}$ and $F_{s}$ stand for the angular cutoff frequency of the filter and sampling frequency, respectively.

Because the drive may operate at different frequencies, the cutoff frequency of the filter should be changed accordingly.

Moreover, both the flux and current signals are filtered with the same type of filter, thus automatically preserving the phase shift between them, which is a necessary condition for the successful use of the diagnostic technique.

2) Transformation to the Clockwise Synchronous Reference Frame: After filtering the stator flux linkage and current signals, the corresponding data are truncated so that they correspond to an integer number of cycles of those functions. The step that follows is the transformation of the current signals to a clockwise synchronous reference frame. For that, the angle $\theta_{s}$ present in the transformation matrix is calculated with the aid of the $d-q$ flux linkage components. Afterwards, the transformation of the current signals from the stationary reference frame to the clockwise synchronous reference frame is performed

$$
\left[\begin{array}{c}
i_{d s}^{-e} \\
i_{q s}^{-e}
\end{array}\right]=\left[\begin{array}{cc}
\cos \left(-\theta_{s}\right) & \sin \left(-\theta_{s}\right) \\
-\sin \left(-\theta_{s}\right) & \cos \left(-\theta_{s}\right)
\end{array}\right]\left[\begin{array}{l}
i_{d s} \\
i_{q s}
\end{array}\right] .
$$

3) Averaging and Transformation to the Counterclockwise Synchronous Reference Frame: Afterwards, the current components $i_{d s}^{-e}$ and $i_{q s}^{-e}$ are averaged and the results are subtracted from the corresponding current components, as in (8)

$$
\left[\begin{array}{c}
i_{d s}^{-e^{*}} \\
i_{q s}^{-e^{*}}
\end{array}\right]=\left[\begin{array}{c}
i_{d s}^{-e}-\operatorname{Mean}\left(i_{d s}^{-e}\right) \\
i_{q s}^{-e^{*}}-\operatorname{Mean}\left(i_{q s}^{-e}\right)
\end{array}\right] .
$$

It should be remarked that in a system with low resources of memory, the mean values of $i_{d s}^{-e}$ and $i_{q s}^{-e}$ can be calculated using the concept of triangulation illustrated in Fig. 2, thus being only necessary to use the coordinates of three different points (the dotted circumference represents the function $i_{q s}^{-e}=f\left(i_{d s}^{-e}\right)$ ). This operation eliminates the negative-sequence component of the motor supply currents. Afterwards, the current signals are transformed to a counterclockwise synchronous reference frame by

$$
\left[\begin{array}{l}
i_{d s}^{e} \\
i_{q s}^{e}
\end{array}\right]=\left[\begin{array}{cc}
\cos \left(2 \theta_{s}\right) & \sin \left(2 \theta_{s}\right) \\
-\sin \left(2 \theta_{s}\right) & \cos \left(2 \theta_{s}\right)
\end{array}\right]\left[\begin{array}{c}
i_{d s}^{-e^{*}} \\
i_{q s}^{-e^{*}}
\end{array}\right] .
$$

In this final reference frame, the quantities $i_{d s}^{e}$ and $i_{q s}^{e}$ should appear as constants, at least in theoretical terms. However, in practice, due to the presence of some subharmonics in the supply currents, in conjunction with the harmonics that the digital filter



Fig. 2. Representation of the current components in the clockwise synchronous reference frame and geometrical calculation of the corresponding average values.

was reduced but not completely eliminated, the coordinates of several points should be averaged to achieve the final values $i_{d s}^{+}$ and $i_{q s}^{+}$.

4) Calculation of the Severity Factor: The calculation of the severity factor involves the determination of the quantities $i_{d s}^{h}$ and $i_{q s}^{h}$. This can be done using the motor parameters determined by the drive during the commissioning phase in conjunction with the measured or estimated rotor speed. The value of the locked-rotor current, which is needed to calculate the severity factor, can also be estimated based on the data recorded during the commissioning phase of the drive.

\section{EXPERIMENTAL RESULTS}

The proposed diagnostic technique was implemented using a TMS320C32 DSP board connected to a 16I/O8 DSPLINK interface board. All of the control and diagnosis blocks were programmed into the DSP and no additional hardware was used besides the one already present for control purposes. The outputs of the DSPLINK board connect to an external buffer circuit before going to the gates of the power switches of a three-phase inverter. The driver circuits assure a dead time of $2.7 \mu$ s between the two power switches of the same leg. The outputs of the inverter feed a 3-hp, four-pole, 230-V, 60-Hz, three-phase induction motor, with its stator windings modified in order to allow the access of different turns to introduce the short circuits.

Figs. 3 and 4 show the current waveforms for the case of a healthy motor and for the case of the motor with one shortcircuited coil (54 short-circuited turns in winding $U-X$, out of 324 turns/phase).

Despite the high extension of the fault, the amplitudes of the fundamental components of the three motor supply currents represented in Fig. 4 are not very much different from the ones for the case of a healthy motor. The most noticeable effect of the fault in the current waveforms is their deformation, mainly due to the existence of third and fifth harmonics introduced by the fault, as can be demonstrated by the analysis of the current spectrum shown in Fig. 5.

The existence of these current harmonics, when the motor develops inter-turn short circuits, is mainly attributed to the poor 


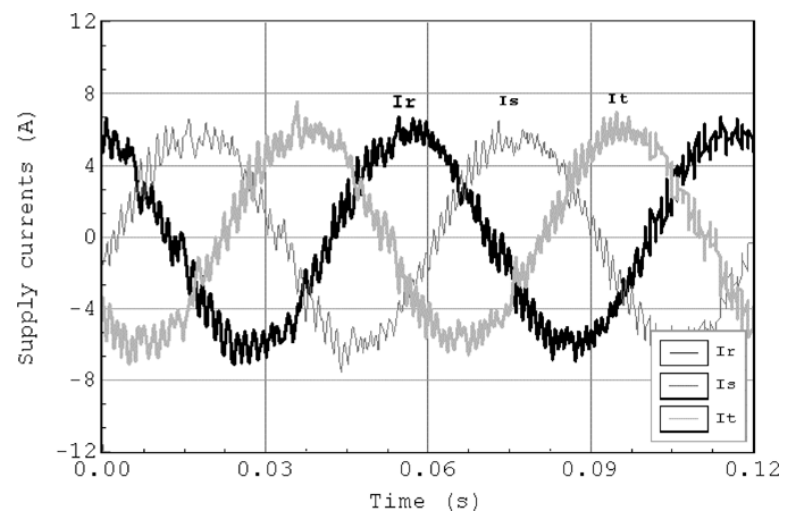

Fig. 3. Motor supply currents for the case of a healthy motor.

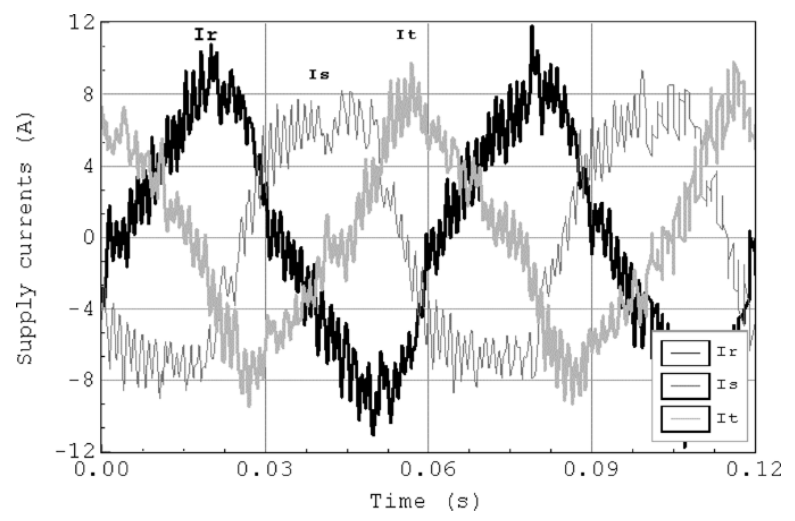

Fig. 4. Motor supply currents for the case of a short-circuited coil.

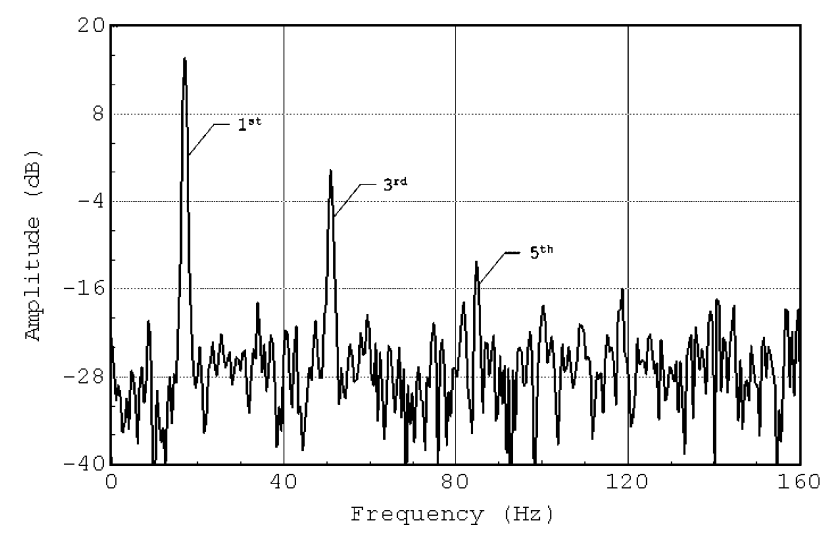

Fig. 5. Current spectrum for the case of a motor with a short-circuited coil.

operation of the torque estimator of the drive that in these adverse conditions cannot accurately estimate the electromagnetic torque developed by the motor using the traditional torque equation used for this purpose [14].

Fig. 6 shows the plot of the flux linkage for the case of the motor running with the same 54 short-circuited turns. As can be recognized, this plot is very similar to the one corresponding to a healthy motor.

Tables I-III present the experimental results as calculated by the DSP, regarding the operation of the DTC induction motor drive, for different extensions of the fault, different motor load levels, and different values of the reference speed of the drive.

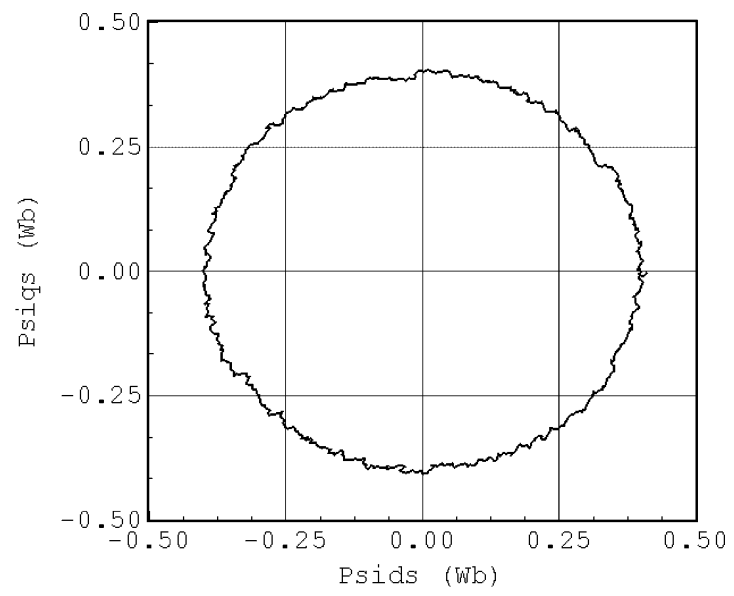

Fig. 6. Estimated stator flux linkage when the motor runs with 54 shorted-circuited turns.

TABLE I

EVOLUTION OF THE SEVERITY FACTOR WITH THE EXTENSION OF THE FAULT (REFERENCE SPEED OF $1000 \mathrm{r} / \mathrm{min}$ )

\begin{tabular}{c|c|c}
\hline $\begin{array}{c}\text { Shorted- } \\
\text { turns }\end{array}$ & $\Delta \underline{i}^{f}=i_{a}^{f}+j i_{q}^{f}(\mathrm{~A})$ & $\begin{array}{c}\text { Severity Factor } \\
(\%)\end{array}$ \\
\hline 0 & 0 & 0 \\
\hline 1 & $0.0275+j 0.0034$ & 0.2775 \\
\hline 5 & $0.0052+j 0.0347$ & 0.3518 \\
\hline $54^{(\mathrm{a})}$ & $0.1612+j 0.3672$ & 4.0160 \\
\hline
\end{tabular}

(a) A short-circuit resistor of $5.3 \Omega$ was used to limit the short-circuit current.

TABLE II

VARIATION OF THE SEVERITY FACTOR WITH THE MOTOR LOAD LEVEL (REFERENCE SPEED OF $1000 \mathrm{r} / \mathrm{min}$ AND 54 SHORTED TURNS)

\begin{tabular}{c|c|c}
\hline Load level & $\Delta \underline{i}^{f}=i_{a}^{f}+j i_{q}^{f}(\mathbf{A})$ & $\begin{array}{c}\text { Severity Factor } \\
(\%)\end{array}$ \\
\hline No-load & $0.1612+j 0.3672$ & 4.016 \\
\hline Load level 1 & $0.1086+j 0.3667$ & 3.831 \\
\hline Load level 2 & $0.1076+j 0.4631$ & 4.638 \\
\hline Load level 3 & $0.1325+j 0.4860$ & 5.045 \\
\hline Load level 4 & $0.1487+j 0.4945$ & 5.171 \\
\hline Load level 5 & $0.1456+j 0.5140$ & 5.350 \\
\hline Load level 6 & $0.1310+j 0.4824$ & 5.006 \\
\hline
\end{tabular}

TABLE III

EVOLUtion of THE SEVERITy FACTOR WITH THE REFERENCE SPEED OF THE DRIVE (54 SHORTED TURNS)

\begin{tabular}{c|c|c}
\hline $\begin{array}{c}\text { Reference } \\
\text { speed (rpm) }\end{array}$ & $\Delta \underline{i}^{f}=i_{\boldsymbol{a}}^{f}+j \ddot{j}_{q}^{f}(\mathrm{~A})$ & $\begin{array}{c}\text { Severity Factor } \\
(\%)\end{array}$ \\
\hline $1000^{(\mathrm{a})}$ & $0.16115+j 0.3672$ & 4.016 \\
\hline $1500^{(\mathrm{a})}$ & $0.17707+j 0.61093$ & 6.37 \\
\hline
\end{tabular}

(a) A short-circuit resistor of $5.3 \Omega$ was used to limit the short-circuit current.

Broadly speaking, for the same load level, the severity factor increases with the extension of the fault. Moreover, the severity factor is just slightly dependent on the motor load level. Theoretically, and according to the results obtained by simulation, the proposed severity factor is almost insensitive to the motor load level. In practice, due to the thermal variations of some 
motor parameters, namely the variations of the rotor resistance, some differences can be seen. It is felt that this aspect can be improved in future implementations of the technique by an adequate compensation of those parameter variations, which was not attempted in this work.

In relation to the operating speed of the drive, that is, in relation to the output frequency of the inverter, the severity factor decreases with the decrease of these values. This is in good agreement with the fact that the short-circuit current also decreases with the output frequency of the inverter. In this way, this behavior of the severity factor does not constitute a limitation to its use.

\section{CONCLUSION}

This work is intended to present a possible implementation of the multiple reference frames theory for the diagnosis of stator faults in DTC induction motor drives. The diagnostic technique is fully integrated into the control system at no additional cost, thus constituting an added value to the final system. Due to the nature of a DTC drive and of the proposed diagnostic technique, most of the quantities calculated for control purposes can also be used for diagnosis. The proposed system has a modular conception in order to allow for its use in the diagnosis of other faults such as eccentricity and rotor faults, subjects that will be addressed in a subsequent paper.

\section{REFERENCES}

[1] M. Arkan and P. Unsworth, "Online stator fault diagnosis in induction motors," Proc. Inst. Elect. Eng., Electr. Power Appl., vol. 148, no. 6, pp. 537-547, Nov. 2001.

[2] A. Stavrou, H. G. Sedding, and J. Penman, "Current monitoring for detecting inter-turn short circuits in induction motors," IEEE Trans. Energy Convers., vol. 16, no. 1, pp. 32-37, Mar. 2001.

[3] T. M. Wolbank, "On-line stator winding faults detection in inverter fed induction motors by stator current reconstruction," in Proc. 9th Int. Conf. Electrical Machines Drives, Canterbury, U.K., Sep. 1-3, 1999, pp. 253-257.

[4] G. B. Kliman, W. J. Premerlani, R. A. Koegl, and D. Hoeweler, "A new approach to on-line turn fault detection in ac motors," in Proc. IEEE Industry Applications Society Annu. Meet., vol. 1, San Diego, CA, Oct. 6-10, 1996, pp. 687-693.

[5] J. S. Kohler, J. Sottile, and F. C. Trutt, "Alternatives for assessing the electrical integrity of induction motors," IEEE Trans. Ind. Appl., vol. 28, no. 5, pp. 1101-1117, Nov./Dec. 1992.

[6] A. Bellini, F. Filippetti, G. Franceschini, and C. Tassoni, "Closed loop impact on the diagnosis of induction motors faults," in Proc. IEEE Industry Applications Society Annu. Meet., vol. 3, Phoenix, AZ, Oct. 3-7, 1999, pp. 1913-1921.

[7] R. M. Tallam, T. G. Habetler, and R. G. Harley, "Stator winding turnfault detection for closed-loop induction motor drives," in Proc. IEEE Industry Applications Society Annu. Meet., vol. 3, Pittsburgh, PA, Oct. 13-18, 2002, pp. 1553-1557.

[8] F. Briz, M. W. Degner, A. Zamarrón, and J. M. Guerrero, "On-line stator winding fault diagnosis in inverter-fed ac machines using high frequency signal injection," in Proc. IEEE Industry Applications Society Annu. Meet., vol. 3, Pittsburgh, PA, Oct. 13-18, 2002, pp. 2094-2101.

[9] P. C. Krause, "Method of multiple reference frames applied to the analysis of symmetrical induction machinery," IEEE Trans. Power App. Syst., vol. PAS-87, no. 1, pp. 218-227, Jan. 1968.

[10] S. D. Sudhoff, "Multiple reference frame analysis of an unsymmetrical induction machine," IEEE Trans. Energy Convers., vol. 8, no. 3, pp. 425-432, Sep. 1993.
[11] P. L. Chapman, S. D. Sudhoff, and C. A. Whitecomb, "Multiple reference frame analysis of nonsinusoidal brushless DC drives," IEEE Trans. Energy Convers., vol. 14, no. 3, pp. 440-446, Sep. 1999.

[12] P. L. Chapman and S. D. Sudhoff, "A multiple reference frame synchronous estimator/regulator," IEEE Trans. Energy Convers., vol. 15, no. 2, pp. 197-202, Jun. 2000.

[13] S. M. A. Cruz and A. J. M. Cardoso, "The method of multiple reference frames applied to the diagnosis of stator faults in three-phase induction motors," in Proc. 4th Int. Power Electronics Motion Control Conf., Xi'an, China, Aug. 14-16, 2004.

[14] — " "Modeling and simulation of DTC induction motor drives for stator winding faults diagnosis," in CD-ROM Conf., Proc. 10th Eur. Conf. Power Electronics Applications, Toulouse, France, Sep. 2-4, 2003.

[15] H. A. Toliyat and T. Lipo, "Transient analysis of cage induction machines under stator, rotor bar and end ring faults," IEEE Trans. Energy Convers., vol. 10, no. 2, pp. 241-247, Jun. 1995.

[16] R. M. Tallam, T. G. Habetler, and R. G. Harley, "Transient model for induction machines with stator winding turn faults," IEEE Trans. Ind. Appl., vol. 38, no. 3, pp. 632-637, May/Jun. 2002.

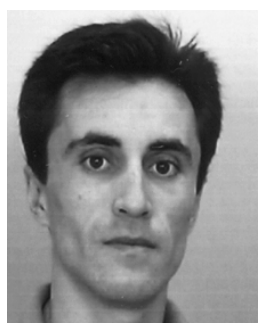

Sérgio M. A. Cruz (S'96-M'04) was born in Coimbra, Portugal, in 1971. He received the E.E. Diploma, M.Sc. degree, and Dr. Eng. degree from the University of Coimbra, in 1994, 1999, and 2004, respectively.

He has been with the University of Coimbra since 1994, where he is currently an Assistant Professor in the Department of Electrical and Computer Engineering. His teaching and research interests cover the areas of rotating electrical machines, power transformers, and electric drives, with special emphasis on diagnostics, modeling, and control. He has authored about 30 technical conference and journal papers.

Dr. Cruz is a Member of the Portuguese Federation of Industrial Maintenance (APMI).

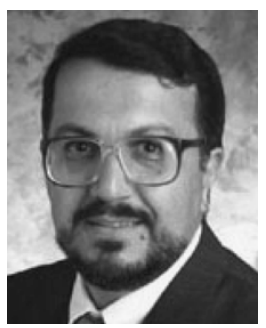

Hamid A. Toliyat (S'87-M'91-SM'96) received the B.S. degree from Sharif University of Technology, Tehran, Iran in 1982, the M.S. degree from West Virginia University, Morgantown, in 1986, and the Ph.D. degree from University of Wisconsin-Madison, Madison, in 1991, all in electrical engineering.

Currently, he is a Professor with the Department of Electrical Engineering, Texas A\&M University, College Station, where he has been since 1994. He was also an Assistant Professor of Electrical Engineering with the faculty of Ferdowsi University of Mashhad, Mashhad, Iran. His main research interests and experience include multiphase variable speed drives for traction and propulsion applications, fault diagnosis of electric machinery, analysis and design of electrical machines, and sensorless variable speed drives. He has published more than 190 technical papers in these fields and has received one U.S. patent. He is actively involved in presenting short courses and consulting in his area of expertise to various industries.

Dr. Toliyat is an Editor of IEEE TRANSACTIONS ON ENERGY CONVERSION, an Associate Editor of IEEE TRANSACTIONS ON POWER ELECTRONICS and a member of the Editorial Board of Electric Power Components and Systems Journal. Dr. Toliyat received the Texas A\&M Select Young Investigator Award in 1999, Eugene Webb Faculty Fellow Award in 2000, and E.D. Brockett Professorship Award in 2002. He has also received the Space Act Award from NASA in 1999 and the Schlumberger Foundation Technical Awards in 2000 and 2001. $\mathrm{He}$ is also Vice-Chairman of IEEE-IAS Electric Machines Committee and a member of Sigma Xi. He is a senior member of the Industrial Applications, Industrial Electronics, Power Electronics, Power Engineering Societies of the IEEE, and the recipient of the 1996 IEEE Power Engineering Society Prize Paper Award for his paper on the Analysis of Concentrated Winding Induction Machines for Adjustable Speed Drive Applications-Experimental Results. 


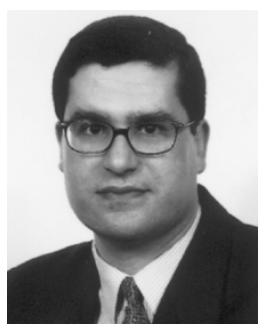

A. J. Marques Cardoso (S'89-A'95-SM'99) was born in Coimbra, Portugal, in 1962. He received the E.E. diploma and the Dr. Eng. degree from the University of Coimbra, in 1985 and 1995, respectively.

Since 1985 , he has been with the University of Coimbra, where he is currently an Associate Professor in the Department of Electrical and Computer Engineering and Director of the Electrical Machines Laboratory. His teaching interests cover electrical rotating machines, transformers, and maintenance of electromechatronic systems, and his research interests are focused on condition monitoring and diagnostics of electrical machines and drives. He is the author of Fault Diagnosis in Three-Phase Induction Motors (Coimbra, Portugal: Coimbra Editora, 1991) (in Portuguese) and about 100 papers published in technical journals and conference proceedings.

Dr. Cardoso is actively involved in the field of standardization on condition monitoring and diagnostics, both at the national and international level, where he has been acting as a convenor of ISO/TC 108/SC 5 Advisory Group D (Condition Monitoring and Diagnostics of Power Transformers) and ISO/TC 108/SC 5 Working Group 10 (Condition Monitoring and Diagnostics of Electrical Equipment), and a member of several Working Groups/Balloting Committees of ISO, IEEE, and CEN. He was a member of the Overseas Advisory Panel of Condition Monitoring and Diagnostic Technology (a journal published by the British Institute of Non-Destructive Testing between 1990 and 1993), and he is currently a member of the Editorial Board of the International Journal of Condition Monitoring and Diagnostic Engineering Management, published by COMADEM International, U.K., an Honorary Member of the International Biographical Centre Advisory Council, Cambridge, U.K., and an Honorary Professor of the Albert Schwitzer International University, Geneva, Switzerland. He is a Member of the New York Academy of Sciences, European Power Electronics and Drives Association (EPE), Electrical Machines and Industrial Drives Committees of the IEEE Industry Applications Society, Portuguese Federation of Industrial Maintenance (APMI), and a Senior Member of the Portuguese Engineers Association (ODE). He has been listed in Who's Who in the World, Who's Who in Science and Engineering, and BEST Europe. 